\title{
IDENTIFIKASI MIKROFILARIA PADA PENDERITA FILARIASIS PASCA PENGOBATAN DI WILAYAH KERJA PUSKESMAS RUM BALIBUNGA
}

\author{
RONY PUASA, SKM.,M.Kes \\ POLTEKKES KEMENKES TERNATE
}

rony_yani@Yahoo.co.id

Latar belakang ; Filariasis adalah penyakit yang disebabkan oleh infeksi parasit nematoda yang tersebar di Indonesia. Penyakit ini jarang terjadi pada anak karena manifestasi klinisnya timbul bertahun-tahun kemudian setelah infeksi. Gejala pembengkakan kaki muncul karena sumbatan mikrofilaria pada pembuluh limfe yang biasanya terjadi pada usia di atas 30 tahun setelah terpapar parasit selama bertahun-tahun. Program eliminasi dilaksanakan melalui pengobatan massal dengan Diethylcarbamazine Citrate (DEC) dan Albendazol setahun sekali selama 5 tahun. Indonesia akan melaksanakan eliminasi penyakit kaki gajah secara bertahap dimulai pada tahun 2002 di 5 kabupaten percontohan. Jika ditemukan mikrofilaril rate $\geq 1 \%$ pada satu wilayah maka daerah tersebut dinyatakan endemis dan harus segera diberikan pengobatan secara masal selama 5 tahun berturut-turut. Dari data Kemeterian Kesehatan tahun 2010 Provinsi Maluku Utara termasuk pada daerah yang memiliki angka kesakitan akibat mikrofilaria patut menjadi perhatian, karena penyakit ini merupakan penyakit menular. Salah satu daerah di Provinsi Maluku Utara yang harus menjadi perhatian akibat kesakitan filariasis adalah Kota Tidore Kepulauan. Pada tahun 2011 Kota Tidore menjadi daerah endemis filariasis dengan miccrofilarial rate diatas $\geq 1 \%$, angka standar nasional menggambarkan daerah endemis filariasis. Tujuan ; tujuan penelitian adalah ; untuk memberikan gambaran mikrofilaria yang ditemukan pada sediaan darah penderita filariasis pasca pengobatan di Wilayah Kerja Puskesmas Rum Balibunga Kecamatan Tidore Utara Kota Tidore Kepulauan. Metode ; penelitian ini merupakan penelitian Deskriptif, dimana hasil dari identifikasi mikrofilaria pada penderita filariasis pasca pengobatan di Wilayah Kerja Puskesmas Rum Balibunga akan digambarkan dalam bentuk jumlah orang dan presentase spesies. Hasil ; pemeriksaan mikrofilaria pada penderita filariasis pasca pengobatan diwilayah kerja Puskesmas Rum Balibunga Kecamatan Tidore Utara Kota Tidore Kepulauan, dari 20 sampel darah responden yang diidentifikasi tidak ditemukan mikrofilaria didalam darahnya. Kesimpulan ; dari hasil penelitian dapat dikatakan akan terjadi penurunan kasus filariasis, hal ini disebabkan sumber penularan atau penderita filariasis tidak ditemukan mikrofilariasis.

Kata Kunci : Mikrofilaria pasca pengobatan 


\title{
THE IDENTIFICATION MICROFILARIA IN FILARIASIS PATIENTS POST TREATMENT OF RUM BALIBUNGA PUSKESMAS AREAS
}

\author{
RONY PUASA, SKM.,M.Kes
}

\section{POLTEKKES KEMENKES TERNATE}

rony_yani@Yahoo.co.id

\begin{abstract}
Background ; Filariasis is a disease caused by parasitic nematode infections spread in Indonesia. This disease is rare in children because the clinical manifestations arise many years later after infection. Symptoms of swelling of the feet arise due to blockage of microfilariae in the lymph vessels that usually occur at the age of 30 years after exposure to parasites for years. The elimination program is carried out through mass treatment with Diethylcarbamazine Citrate (DEC) and Albendazol once a year for 5 years. Indonesia will gradually implement the elimination of elephantiasis starting in 2002 in 5 pilot districts. If microfilateralil rate $\geq 1 \%$ is found in one area, then the area is declared endemic and must be given treatment on a mass basis for 5 consecutive years. From data from the Ministry of Health in 2010, North Maluku Province, including in areas that have morbidity rates due to microfilaria should be a concern, because this disease is an infectious disease. One area in North Maluku Province that must be a concern due to filariasis pain is the City of Tidore Islands. In 2011 the city of Tidore became a filariasis endemic area with a miccrofilarial rate above $\geq 1 \%$, a national standard figure describing filariasis endemic areas. Purpose ; the research objectives are; to provide an overview of microfilariae found in the blood preparations of post-treatment filariasis sufferers in the Working Area of the Rum Balibunga Health Center, North Tidore District, Tidore Islands City. Method ; this research is descriptive research, where the results of identification of microfilariae in post-treatment filariasis patients in the working area of the Balibunga Rum Health Center will be described in the form of the number of people and the percentage of species. Results; Microfilariae examination in post-treatment filariasis patients in the working area of Rum Balibunga Health Center North Tidore Subdistrict, Tidore Islands City, of 20 blood samples of respondents identified as not found microfilariae in their blood. Conclusion; from the results of the study it can be said that there will be a decrease in filariasis cases, this is due to the source of transmission or patients with filariasis not found microfilariasis.
\end{abstract}

Keywords: Post-treatment microfilaria

\section{A. Pendahuluan}

Filariasis adalah penyakit yang disebabkan oleh infeksi parasit nematoda yang tersebar di Indonesia. Penyakit ini jarang terjadi pada anak karena manifestasi klinisnya timbul bertahun-tahun kemudian setelah infeksi. Gejala pembengkakan kaki muncul karena sumbatan mikrofilaria pada pembuluh limfe yang biasanya terjadi pada usia di atas 30 tahun setelah terpapar parasit selama bertahun-tahun, (Widoyono, 2008). Program eliminasi dilaksanakan melalui pengobatan massal dengan Diethylcarbamazine Citrate (DEC) dan Albendazol setahun sekali selama 5 tahun, (Depkes RI, 2006). Penyakit ini ditemukan hampir di seluruh wilayah Indonesia, berdasarkan laporan tahun 2009, tiga provinsi dengan jumlah kasus terbanyak filariasis adalah Nanggroe Aceh Darussalam (2.359 orang), Nusa Tenggara Timur (1.730 orang) dan Papua (1.158 orang). Tiga provinsi dengan kasus terendah adalah Bali (18 orang), Maluku Utara (27 orang), dan Sulawesi Utara (30 orang), dapat dilihat pada Gambar 2. Kejadian filariasis di NAD sangat menonjol bila dibandingkan dengan provinsi lain dan merupakan provinsi dengan jumlah kasus tertinggi di seluruh Indonesia. Hal ini memerlukan perhatian untuk ditindak lanjuti, dan dicari kemungkinan penyebabnya, (Kementerian Kesehatan RI, 2010). Indonesia akan melaksanakan eliminasi penyakit kaki gajah secara bertahap dimulai pada tahun 2002 di 5 kabupaten percontohan. Jika ditemukan mikrofilaril rate $\geq 1 \%$ pada satu wilayah maka daerah tersebut dinyatakan endemis dan harus segera diberikan pengobatan secara masal selama 5 tahun berturut-turut. Dari data Kemeterian Kesehatan tahun 2010 Provinsi Maluku Utara termasuk pada daerah yang memiliki angka kesakitan akibat mikrofilaria patut menjadi perhatian, karena penyakit ini merupakan penyakit menular. Salah satu daerah 
di Provinsi Maluku Utara yang harus menjadi perhatian akibat kesakitan filariasis adalah Kota Tidore Kepulauan. Pada tahun 2011 Kota Tidore menjadi daerah endemis filariasis dengan miccrofilarial rate diatas $\geq 1 \%$, angka standar nasional menggambarkan daerah endemis filariasis

\section{B. Metode}

Penelitian ini merupakan penelitian Deskriptif, dimana hasil dari identifikasi mikrofilaria pada penderita filariasis pasca pengobatan di Wilayah Kerja Puskesmas Rum Balibunga akan digambarkan dalam bentuk jumlah orang dan presentase spesies.

C. Hasil Penelitian dan Pembahasan

1. Hasil Penelitian

Penelitian yang dilaksanakan di Puskesmas Rum Balibunga Kecamatan Tidore Utara Kota Tidore Kepulauan di mulai pada tanggal 16 Juni sampai 30 Juni 2015. Data penelitian diperoleh dari pengambilan sampel terhadap subjek penelitian berupa darah perifer penderita filariasis pasca pengobatan di Wilayah Kerja Puskesmas Rum Balibunga Kecamatan Tidore Utara. Darah perifer yang diambil sebanyak $60 \mu \mathrm{l}$ dan selanjutnya di buat sediaan darah dengan bentuk 3 garis sejajar pada kaca objek. Setelah dilakukan proses pewarnaan sediaan darah, dilanjutkan dengan identifikasi, sehingga diperoleh hasil sebagai berikut ;

Tabel 5.2 ; Hasil Pemeriksaan Mikrofilaria Pada Penderita Filariasis Pasca Pengobatan Diwilayah Kerja Puskesmas Rum Balibunga Kecamatan Tidore Utara Kota Tidore Kepulauan.

\begin{tabular}{|c|c|c|c|c|c|c|c|}
\hline No & \multirow{2}{*}{ Nama } & \multirow{2}{*}{ J } & \multirow{2}{*}{ Umur } & Alamat & \multicolumn{2}{|c|}{ Hasil } & Spe \\
\cline { 5 - 7 } & & K & & & $(+)$ & $(-)$ & sies \\
\hline 1. & Tn A & L & $26 \mathrm{Th}$ & $\begin{array}{c}\text { Kel. } \\
\text { Rum }\end{array}$ & & $\sqrt{ }$ & \\
\hline 2. & Tn B & L & $64 \mathrm{Th}$ & $\begin{array}{c}\text { Kel. } \\
\text { Rum }\end{array}$ & & $\sqrt{ }$ & \\
\hline 4 & Tn C & L & $43 \mathrm{Th}$ & $\begin{array}{c}\text { Kel. } \\
\text { Rum }\end{array}$ & & $\sqrt{ }$ & \\
\hline
\end{tabular}

\begin{tabular}{|c|c|c|c|c|c|}
\hline 5. & Ny E & $\mathrm{W}$ & $36 \mathrm{Th}$ & $\begin{array}{l}\text { Kel. } \\
\text { Rum }\end{array}$ & $\sqrt{ }$ \\
\hline 6. & Tn F & $\mathrm{L}$ & $43 \mathrm{Th}$ & $\begin{array}{l}\text { Kel. } \\
\text { Rum }\end{array}$ & $\sqrt{ }$ \\
\hline 7. & $\operatorname{Tn} G$ & $\mathrm{~L}$ & $65 \mathrm{Th}$ & $\begin{array}{l}\text { Kel. } \\
\text { Jaya }\end{array}$ & $\sqrt{ }$ \\
\hline 8. & $\mathrm{Ny} \mathrm{H}$ & $\mathrm{W}$ & $30 \mathrm{Th}$ & $\begin{array}{l}\text { Kel. } \\
\text { Rum }\end{array}$ & $\sqrt{ }$ \\
\hline 9. & Tn I & $\mathrm{L}$ & $24 \mathrm{Th}$ & $\begin{array}{l}\text { Kel. } \\
\text { Rum }\end{array}$ & $\sqrt{ }$ \\
\hline 10. & Tn J & $\mathrm{L}$ & $42 \mathrm{Th}$ & $\begin{array}{l}\text { Kel. } \\
\text { Rum }\end{array}$ & $\sqrt{ }$ \\
\hline 11. & Ny K & $\mathrm{W}$ & $35 \mathrm{Th}$ & $\begin{array}{l}\text { Kel. } \\
\text { Rum }\end{array}$ & $\sqrt{ }$ \\
\hline 12. & Ny L & $\mathrm{W}$ & $39 \mathrm{Th}$ & $\begin{array}{l}\text { Kel. } \\
\text { Rum }\end{array}$ & $\sqrt{ }$ \\
\hline 13. & $\operatorname{Tn} \mathrm{M}$ & $\mathrm{L}$ & $49 \mathrm{Th}$ & $\begin{array}{l}\text { Kel. } \\
\text { Rum }\end{array}$ & $\sqrt{ }$ \\
\hline 14. & $\mathrm{Ny} N$ & $\mathrm{~W}$ & $29 \mathrm{Th}$ & $\begin{array}{l}\text { Kel. } \\
\text { Rum }\end{array}$ & $\sqrt{ }$ \\
\hline 15. & $\mathrm{Ny} \mathrm{O}$ & $\mathrm{W}$ & $30 \mathrm{Th}$ & $\begin{array}{l}\text { Kel. } \\
\text { Rum }\end{array}$ & $\sqrt{ }$ \\
\hline 16. & Ny P & $\mathrm{W}$ & $37 \mathrm{Th}$ & $\begin{array}{l}\text { Kel. } \\
\text { Rum }\end{array}$ & $\sqrt{ }$ \\
\hline 17. & Ny Q & $\mathrm{W}$ & $33 \mathrm{Th}$ & $\begin{array}{l}\text { Kel. } \\
\text { Rum }\end{array}$ & $\sqrt{ }$ \\
\hline 18. & Tn R & $\mathrm{L}$ & $60 \mathrm{Th}$ & $\begin{array}{l}\text { Kel. } \\
\text { Rum }\end{array}$ & $\sqrt{ }$ \\
\hline 19. & $\operatorname{Tn} S$ & $\mathrm{~L}$ & $54 \mathrm{Th}$ & $\begin{array}{l}\text { Kel. } \\
\text { Rum }\end{array}$ & $\sqrt{ }$ \\
\hline 20. & Ny T & $\mathrm{W}$ & $40 \mathrm{Th}$ & $\begin{array}{l}\text { Kel. } \\
\text { Rum }\end{array}$ & $\sqrt{ }$ \\
\hline
\end{tabular}

Sumber : Data Primer 2015

Tabel 5.2, menunjukan hasil pemeriksaan mikrofilaria pada penderita filariasis pasca pengobatan diwilayah kerja Puskesmas Rum Balibunga Kecamatan Tidore Utara Kota Tidore Kepulauan, dari 20 sampel darah responden yang diidentifikasi tidak ditemukan mikrofilaria didalam darahnya.

Tabel 5.3 ; Distribusi Hasil Pemeriksaan Mikrofilaria Pada Penderita Filariasis Pasca Pengobatan Diwilayah Kerja Puskesmas Rum Balibunga Kecamatan Tidore Utara Kota Tidore Kepulauan

\begin{tabular}{|c|c|c|}
\hline \multirow{2}{*}{ Hasil } & \multicolumn{2}{|c|}{ Jumlah } \\
\cline { 2 - 3 } & n & $\begin{array}{c}\text { Persentase } \\
(\%)\end{array}$ \\
\hline Positif & $\mathbf{0}$ & $\mathbf{0 \%}$ \\
\hline Negatif & $\mathbf{2 0}$ & $\mathbf{1 0 0} \%$ \\
\hline Total & $\mathbf{2 0}$ & $\mathbf{1 0 0 \%}$ \\
\hline
\end{tabular}


Sumber : Data Primer 2015

Tabel 5.3, menunjukan bahwa dari 20 sampel darah penderita filariasis pasca pengobatan tidak diperoleh sampel yang positif atau negatif $100 \%$

Tabel 5.4 ; Distribusi Penderita Filariasis Pasca Pengobatan Di Wilayah Kerja Puskesmas Rum Balibunga Kecamatan Tidore Utara Kota Tidore Kepulauan Berdasarkan Jenis Kelamin.

\begin{tabular}{|c|c|c|}
\hline \multirow{2}{*}{ Jenis kelamin } & \multicolumn{2}{|c|}{ Jumlah } \\
\cline { 2 - 3 } & $\begin{array}{c}\text { Penderita } \\
\text { filariasis } \\
\text { Pasca } \\
\text { pengobatan }\end{array}$ & Persentase \\
$(\%)$ \\
\hline Laki-laki & 11 & $55 \%$ \\
\hline Perempuan & 9 & $45 \%$ \\
\hline total & 20 & $100 \%$ \\
\hline
\end{tabular}

Sumber : Data Primer 2015

Tabel 5.4, menunjukan bahwa dari distribusi berdasarkan jenis kelamin yang paling banyak menderita filariasis adalah pria dari pada wanita dengan jumlah pria sebanyak $11(55 \%)$ sedangkan wanita sebanyak $9(45 \%)$.

\section{Pembahasan}

Filariasis atau yang lebih dikenal dengan penyakit kaki gajah merupakan penyakit menular menahun yang disebabkan oleh infeksi cacing filaria dan ditularkan oleh berbagai jenis nyamuk. Penyakit ini dapat menimbulkan cacat seumur hidup berupa pembesaran tangan, kaki, payudara, dan buah zakar. Cacing filaria hidup disaluran dan kelenjar getah bening. Infeksi cacing filaria dapat menyebabkan gejala klinis akut dan atau kronik, (Depkes RI, 2005).

pengobatan filariasis adalah mengeliminasi filariasis di Indonesia. Eliminasi ini dicapai dengan menerapkan dua strategi utama, yaitu memutus rantai penularan filariasis melalui pengobatan massal di daerah endemis dan membatasi kecacatan melalui penatalaksanaan kasus klinis filariasis, (KemenKes RI, 2007)

Penderita filariasis biasanya tidak menunjukan gejala klinis atau disebut sebagai asimtomatis, hal ini disebabkan oleh kadar mikrofilaria yang terlalu sedikit, (Widoyono, 2008). Oleh karena itu, untuk mendiagnosa penyakit filariasis yang paling penting adalah pemeriksaan secara mikroskopis dengan pembuatan sediaan darah yang diambil pada malam hari yakni ; pukul $22.00-24.00$.

Penelitian ini dilakukan terhadap 20 responden yang telah bersedia untuk diambil sampel. Sampel yang digunakan adalah darah perifer penderita filariasis pasca pengobatan yang diambil pada malam hari, dan langsung dibuat sediaan berbentuk 3 garis sejajar, kemudian dikeringkan selama 24 jam. Sediaan yang telah kering, kemudian dilisiskan kembali, selanjutnya diwarnai dengan giemsa $20 \%$. Sediaan diperiksa dibawah mikroskop dengan pembesaran rendah $10 \times 10$.

Pada tabel 5.2 menunjukan bahwa dari 20 sampel yang diidentifikasi mikrofilarianya tidak ditemukan mikrofilaria. Hal ini menunjukan program eliminasi filariasis di Wilayah Puskesmas Rum Balibunga terhadap penderita yang menjadi sampel penelitian ini berhasil. Keberhasilan ini dapat disebabkan oleh dukungan dari penderita dan keluarga itu sendiri serta pengawasan dari petugas puskesmas. Dukungan dari semua pihak sangat dibutuhkan dalam program eliminasi filariasis ini, selain dukungan moral dari keluarga dan petugas tidak kalah penting adalah dukungan obat untuk membunuh cacing didalam darah.

Pemerintah telah mendukung dengan diberi obat anti filariasis di daerah endemis maupun non endemis diberikan DEC 3x1 tablet $100 \mathrm{mg}$ selama 10 hari dan parasetamol $3 \times 1$ tablet $500 \mathrm{mg}$. Bila penderita berada di daerah endemis maka pada tahun berikutnya diikutsertakan dalam pengobatan massal dengan DEC, Albendazole dan Parasetamol sekali setahun minimal 5 tahun secara berturut turut, (DepKes RI, 2009).

Pada tabel 5.3, menunjukan bahwa persentase hasil pemeriksaan mikrofilaria pada 
penderita filariasis pasca pengobatan tidak ditemukan responden yang didalam darahnya mengandung mikrofilaria $0 \%$, hal ini menunjukan terjadinya penurunan kasus filariasis bagi yang mengkonsumsi obat anti filariasis dengan teratur.

Pada tabel 5.4, menunjukan bahwa distribusil berdasarkan jenis kelamin yang paling banyak menderita filariasis adalah pria dari pada wanita dengan jumlah pria sebanyak 11 orang $(55 \%)$ sedangkan wanita sebanyak 9 orang (45\%). Hal ini dapat dijelaskan bahwa diwilayah kerja Puskesmas Rum Balibunga laki-laki lebih banyak yang menderita filariasis dibandingkan wanita. Hal dapat disebabkan oleh aktifitas laki - laki yang lebih banyak di luar rumah terutama pada malam hari yang dimungkinkan tergigit oleh nyamuk yang menganduk mikrofilaria. Keterpaparan terhadapa nyamuk infeksius sangat berisiko terhadap penyakit filariasis.

Selain jenis kelamin yang merupakan salah satu faktor penyebab terjadinya filariasis ada juga faktor lainya yang mendukung terjadinya filariasis seperti lingkungan. Di wilayah kerja Puskesma Rum Balibunga khususnya Kelurahan Rum terdapat beberapa rawa, karena dengan keberadaan rawa kepadatan nyamuk lebih tinggi. Oleh sebab itu lingkungan juga merupakan faktor risiko terhadap kejadian filariasis di wilayah kerja Puskesmas Rum Balibunga Kecamatan Tidore Utara Kota Tidore Kepulauan.

Adapun keterbatasan dalam penelitian ini adalah tidak semua penderita filariasis yang telah diobati dapat kami jadikan sampel atau responden dikarenakan waktu penelitian kami yang terbatas dan saat penelitian mereka bedara diluar daerah atau pergi kekebun yang jauh dari lokasi penelitian.

\section{Kesimpulan dan Saran}

\section{Kesimpulan}

Berdasarkan hasil penelitian yang telah diperoleh, maka dapat disimpulkan sebagai berikut :

a. Penderita filariasis setelah mengkonsumsi obat anti filariasis 3 tahun yang lalu dengan teratur dapat menyebabkan matinya mikrofilaria didalam sampel darahnya.

b. Dari 20 penderita filariasis pasca pengobatan yang dijadikan responden tidak ditemukan mikrofilaria dalam sampel darahnya.

c. Dari hasil penelitian dapat dikatakan akan terjadi penurunan kasus filariasis, hal ini disebabkan sumber penularan atau penderita filariasis tidak ditemukan mikrofilariasis, namun faktor - faktor lain yang dapat menyebabkan peningkatan kasus harus di hindari.

d. Pengeringan sediaan darah minimal 24 jam sudah cukup baik untuk hasil identifikasi.

\section{Saran}

Berdasarkan kesimpulan dari penelitian ini maka perlu disarankan adalah :

a. Melakukan surveilans tentang filariasis secara berkala di Wilayah Puskesmas Rum Balibunga, untuk menemukan kasus secara dini sehingga dapat ditangani sebelum penyakitnya meningkat pada stadium yang lebih parah.

b. Melakukan edukasi terhadap masyarakat tentang risiko yang dapat ditimbulkan oleh penyakit filariasis dan faktor - faktor penyebab penularan.

c. Melakukan advokasi kepada pemerintah daerah untuk bekerjasama dalam menghilangkan tempat hidup vektor, seperti air sungai yang tidak mengalir.

\section{E. Daftar Pustaka}

1. Anonymous. 2009. Nemanthelminthes. Jakarta. (online) http://infovelt.blogspot.com

2. Depkes RI. 2006. "Epidemiologi Filariasis". Jakarta.(online) https;//staypublichealth.blogspot.in/2013/0 3/sanitasi-filariasis.

3. Depkes RI. 2005. "Profil Kesehatan Indonesia". Jakarta.(online) https://kotakpencil.wordpress.com/kesehat an/penyakit-kaki-gajah-filariasis-atauelephantiasis/ 
4. Depkes RI. 2009. "Profil Kesehatan Indonesia". Jakarta.(online)

5. https://silviamona.wordpress.com/2013/07/ 22/penyakit-filariasis

6. Gandahusada S, dkk. 2006. Parasitologi Kedokteran. Cetakan ke-IV. Jakarta: Penerbit FKUI.

7. Hadidjaja P. 2011. "Dasar Parasitologi Klinik, Edisi Pertama”. FKUI. Jakarta

8. Hendra, W.2013. "Buku Parasitologi Kedokteran". FKUI. Jakarta

9. Ideham B. 2007. "Filariasis, Kelas Nematoda. Dalam : Helmintologi Kedoktera"n. Surabaya

10. Kemenkes RI. 2006. "Epidemiologi Filariasis". Jakarta

11. Kemenkes RI. 2007."Pedoman Penanggulangan Kejadian Ikutan Pasca Pengobatan Filariasis". Jakarta

12. Nasry. 2006. "Pengantar Epidemiologi Penyakit Menular". Jakarta

13. Onggowaluyo, J.S. 2002. Parasitologi Medik I Helmintologi. Jakarta : Penerbit EGC

14. Safar, 2010. Penyakit Parasit Yang Kurang diperhatikan di Indonesia. Jakarta : Penerbit UGM Press

15. Soeyoko, D.T.M\&H, S.U, 2002. "Penyakit Kaki Gajah, Filariasis Limfatik, Permasalahan Dan Alternative Penanggulangannya”. Fakultas Kedokteran Universitas Gadjah Mada

16. Sudomo M., 2008. "Penyakit Parasit Yang Kurang diperhatikan di Indonesia". Jakarta

17. Sulistyaningsih. 2011. "Metodologi Penelitian Kebidanan: KuantitatifKualitatif". Yogyakarta

18. Susanto I. 2008. "Parasitologi Kedokteran, Edisi IV". FKUI

19. WHO. 2009. "Global Programme to Eliminate Lymphatic Filariasis".

20. Widoyono. 2008. "Penyakit Tropis, Epidemiologi, Penularan, Pencegahan, \& Pemberantasannya". Jakarta 